\title{
The Comparative Study on Settings of Homosexual Roles in Hong Kong, Taiwan and Mainland's TV Series
}

\author{
Chan Wang \\ Heihe University \\ Heihe, China
}

\begin{abstract}
The effects of civilization of social environment and western culture make Chinese values develop diversely. And the topic of homosexuality is also on the way to publicity from sensitivity. Of course, this kind of public discussion exists a lot of restrictions of propaganda way, target audiences, acceptance, opportunities and fields. Because of the differences between social culture and political context, there is a dear distinction among Hong Kong, Tai Wan and mainland in terms of this topic. Especially the discrepancy of homosexual image is representative on the TV screen among mainland, Hong Kong and Tai Wan. The paper researching homosexual roles in TV series between two areas of China, analyzes contrastively for four aspects of roles, TV series themes, proportion of male and female roles and the degree of characterization, aiming at exploring the different thoughts of creating marginal group's movie arts in Hong Kong, Tai Wan and mainland.
\end{abstract}

Keywords-Hong Kong, Tai Wan and mainland; TV series; homosexuality; the screen image

\section{INTRODUCTION}

Since ancient times, both in the East and the West, homosexuality is a sensitive and marginal subject. The homosexual group in Asian culture, which suffers from pushing aside by mainstream of heterosexual culture, is outside of expressing mainstream discourse without understanding and attention. The topic about homosexuality often suffering embarrassed and adding a layer of secret color, is free from the edge of mainstream culture. However, with the spreading of mass media, the abuse of video and text inducing by social romantic atmosphere, the homosexual group appears in public more and more. The TV series involving the homosexuality come into views gradually and arouse people's concern and discussion.

Through observing the history of western and eastern homosexuality, we may find that there is a certain difference between them. In terms of basic attitude towards homosexuality, in the west, while the middle age was a painful purgatory era for homosexuality, the ancient Greece, Renaissance and the times since the 1960's were more comfortable periods for their living. The understanding of homosexuality experiences a loose-severe- tolerant process.
The ancient China remained a ambiguous tolerant attitude, and became severe since modern times.

Comparing to China, western movie arts express homosexuality more directly and abundantly. Since the 19990's, western homosexuality presented a blatant and exciting culture prominence, and tended to march forward mainstream culture. A word of "homosexuality" is no longer repulsive and taboo full of derogatory sense. The making, spreading and influence of homosexuality videos are increased significantly, which shows the strong visibility of homosexuality.

The review of one hundred year's history of Chinese film development, the homosexuality discourse is negligible. Since the new century, Chinese homosexuality movies have risen rapidly. Comparing to the western, Chinese movies still present homosexuality basically. With the open of public opinions and permission of mainstream medias, the expressions of homosexuality in Chinese plays and movies from shamanic to triumphant, experiencing three periods of speechless and ambiguity, coming out of the closet and popularity, has a distinctive feature different from western movies - hidden "ambiguity". In a word, Chinese movies present homosexuality pretty good, while Chinese TV series shows flimsy on creating and expressing homosexuality. Today, the amount of Chinese TV series with homosexual roles shows an increasing trend and the amount of TV series with plots of homosexuality increases more obviously. Thereinto, TV series in Hong Kong and Tai wan are much more than mainland's relatively. The showing of this phenomenon represents the social significance and the political conte xt, not by accident.

After my researching of homosexual roles and plots in TV screen and Chinese TV series, it is found that there are some differences between Hong Kong, Tai wan and mainland's TV plays.

\section{DIFFERENT SCENES OF HOMOSEXUAL ROLES}

Homosexual roles in Hong Kong and Tai Wan's TV series occasionally are main characters, while in main land's TV series all of them are supporting roles. Comparing to mainland's TV series, Hong Kong and Tai Wan's TV plays get involved in more complicated sexual preference, such as 
homosexuality, transsexual and transvestism. Homosexual roles in mainland's TV series are almost supporting roles, just as a little detail and commercial stunt; while there are more scenes of homosexual roles in Hong Kong and Tai Wan TV series, either relative with main characters directly, or just as main characters themselves. It is closely connected with specific politics, economy, civilization climate and the production and management system in film.

It is a progressive process that homosexual characters and plots happen in the Chinese TV series. Since 1990's, there are some homosexual plots appeared in Hong Kong TVB series, generally as supporting roles or their partners. At the beginning of 21 century, it has changed that homosexual characters and plots develop a necessary part from a little proportion in lots of TV series played by TVB. For example, in 2002, Tang Wei (by Lin Chenwei) played as a homophile in Burning Flame II had important scenes and died of AIDS finally. In 2002, Good Against Evil, Rong Xiaodian (by Wu Meiyan) was a good friend of the heroine at the start, then turned to be a role unrequitedly loving the heroine. In the Hong Kong TV series attracting audience with plot twists, these homosexual roles actually reaches these effects. In 2003, the TV play Crystal Boy setting the homosexual role as the first hero played at golden time eight o'clock by Tai Wan's public television, explored the survival state and emotional world. The TV play adapted according to Bai Xianyong's the same orig inal novel, acted by many powerful actors and idol actors, is especially concerned by China.

Although presenting homosexual plots from the front side don't conform to China's conditions, SARFT saves some personal space to this investigation, after national Ministry of Public Health removing homosexuality from psychosis since 2001. In 1999, Palace of Desire directed by Li Shaohong had a close attention of all parties and an outstanding viewing. In the seventh set, Li Hong had a mental disorder suffering from mother's pressure, and died of blood mysteriously. His child lover He Huan (by Liu Chang) tragically begged the empire to die and bury with $\mathrm{Li}$ Hong. In the play, He Huan yelled at Li Zhi and Wu Zetian loudly: "I'm the servant of the prince, not only his servant, but also his lover." Many audiences couldn't forget it up to now, and were moved by their romance. The third childe Jin Zhenpeng(by Yang Peiheng) in the play The Story of a Noble Family had a homosexual tendency of loving female impersonators. Although this kind of character gets people's attention, it is always a supporting role in the play.

In 31th, December 2015, both of China TV Production Industry Association and China Radio and Television Union made a rule The General Content of TV Plays Making carried out from April 3, 2016. TV series are forbidden to "advertise obscenity and vulgarity", including "showing unusual sexual relationship, sex behavior covering incest, homosexuality, sexual perversion, assault, abuse and violence". The rule doesn't have compulsive bonding, but it still influences the expressing of homosexuality directly in TV plays.

\section{DIFFERENT THEME OF HOMOSEXUALITY IN TV PLAYS}

Homosexual images in Hong Kong and Tai Wan's TV series appear on policemen and bandits drama and family ethics drama, while they are almost presented on historical play in mainland. It is fe wer that TV series takes homosexual stories as a core theme, but homose xual characters appear on various TV themes as supporting roles.

At the end of the last century, the golden time of Hong Kong films, TVB pushed out a series of profession drama with Hong Kong's feature, the most classics TVB policemen and bandits drama, such as Defective Investigation Files, Forensic Heros, Line Walker, which all won fiery ratings. TV plays involved in this theme taking main characters' working life and emotional entanglements as a mainline through out, with lots of stories of main characters' policemen work, get involved in many social phenomenon and groups, including homosexuality. For example, Kang Baoqi (by Yan Huiming) in Defective Investigation Files II, Mai Yongfu (by Li Nuoyi) in Forensic Heros are gay roles in the cases. However, such policemen and bandits drama often performs homosexual in distortion, and sometimes mocking and defaming, in order to achieve the main characters and plots. Homosexual in plays almost negative images, even suspects, finally didn't escape from ends like suicide, murdering, under arrest and loneliness elderly.

In Tai Wan, many of TV series including homosexual plots are family ethics drama, for example, Crystal Boy remained. Though the main hero is a homosexual, as the author said:"In the Crystal Boy, I mainly describe a fatherson relationship, while extending the father and son as: the father presents an attitude, a value in China's society, especially the attitude toward next generation and homosexual children — the conflicts between father and son, actually kind of conflict of person and society". In 2002, the drama film Dance of the Vergin directed by Cao Ruiyuan, represented that two girls' life tracks inter-weaved together without separating. The play showing the father and daughter affection, females' friendship, the love between male and female and homosexual love, took the audience to feel the touch life stories.

In ancient China, the tolerance toward homosexuality makes the social ethos of gay popularity spread. Because of the limitations of social ethos, moral senses, the time constraints and writers themselves, many works dealing with homosexuality appear contradicted. The love story between the first birth of emperor Tang Taizong, Li Chengqian and his boy Chen Xin was a truth, also recorded by The Biography of Li Chenqian. So the TV plays describing this period of history, basically mentioned this unofficial history, such as 1995 CCTV edition Empress Wu, 2006Government of Zhenguan and 2004 The Legend of Empress Wu. In 2007, Xun Huisheng played by CCTV eighth, which described the whole legend life of Xun, turned up a debatable plot of indecency boy in the second set, that is a real reflection of male popularity in the operatic circle at past. In the Chinese homosexual plays, drama is a unique image. Both the 
disguise show of Chinese operas and the single environment of operatic circle, provide a possibility for ho mosexuality.

\section{DIFFERENT PROPORTION OF MALE AND FEMALE HOMOSEXUAL CHARACTERS}

In Hong Kong TV series, the appearance of female homosexuality is basically same as male's, while lesbian roles rarely are shown on mainland plays. Now among the homosexual discourse in the Chinese plays, though gay and lesbian are allies of objecting heterosexuality, the voice of gay is a dominant position and lesbian's support. Therefore, lesbian are usually unable to pursue their true feelings with the end of heterosexual marriages, or remain the homosexuality with bowing to heterosexual marriages, which are difficult to get rid of confusing destiny. In the play, lesbian's emotional description $\mathrm{s}$ is discussed less seriously by erotic way, just to satisfy the spying desire of straight men.

Recently, the lesbian discourse in the Chinese TV series has gradually increased and the works of facing lesbian or female friendship also appear constantly. In the contrast, Hong Kong and Tai Wan TV series involved in homosexual theme, the characters have a balance of male and female ratio. Either some gay roles such as, Long Yangjun (by Gai Minghui) in 2001 A Step into the Past, Peng Guohui (by Cai Kangnian) in 2002 The Negotiator, You Ridong (by Huang Debing) in 2008 Bedecked with Jewels, or some lesbian roles such as, Fang Xinmei (by He Aoer)in 2008 Pages of Treasures, Fang Siyao (by Li Liangjin) and Jiang Xiaoting (by Chen Peiqi)in 2013 The World's Love, Pei Youxin (by Li JingTian) and Lu Weixuan (by Mo Yunwen) in 2015 《Love or Spend $\gg$.

In 2014, the domestic idol TV drama 《Sixteen Summers $\gg$ played by Tai Wan's public television gave two different answers on describing female's friendship. In the play, the most important female friend of hero ine Tang Jia Ni (Lin Xin Ru acting), Zheng RuiRui (Xu WeiNi acting)'s emotional ending has been doubted, cause the crew made two editions in the post production. In Tai Wan's edition, she was always having a crush on her friends; while in mainland, she loved her best friend's ex-husband. This method of cutting could be seen as a mirror contrasting two straits media atmosphere.

In the main land's TV series, there is a little lesbian role, or just a homosexual tendency with sharp-cut marginalization. This kind of series often try to keep two women relationship in same-sex bonds safely, actually they're a couple in the spirit without the word "love" and non-sex. On the one hand, it shows weakness of lesbian's discourse; on the other hand, it shows "tolerance". This tolerance doesn't mean more understanding and permission to lesbian, rather than a "comforting" combination to lesbian in the male's social order. For example, Jing princess (Hao Lei acting) had a deep and dubious relationship with Hua ShuZi (Cui Bo acting) in Son of Heaven, Leng XiaoXing (Han Xue acting) had a more than sister kinship with Xue CaiYue(Lin XinRu acting) in Flying Daggers.

\section{DIFFERENT DEGREE OF CHARACTERIZING}

The homosexual images in Hong Kong TV series appear with their identity, and their characters are more complete, while the homosexual images are only the tendency with vague character describing. In the 1990s, the homosexuality "come out of the closet" and happen in Chinese film works. The homosexual discourse increases rapidly, which is greatly hot at a time. Up to now, the self-identity, characteristic, drama plots and images of TV series involved in homosexual factor are presented clearer. Though some of play creators express the homosexual emotion and relationship with heterosexual habitual version and thinking, this creating tendency reflects their real state and influences of heterosexual culture order at some degree, which usually tends to tag and alien homosexuality, such as sissy and tomboy.

In 2001, Against Women, lesbian as main roles at the first time in Tai Wan's TVhistory, where two heroines fell in a pure without regret, painful love, surprised many audiences. Ding Tianshi (by Liu Yue), as a heroine, with a sharp description of characters, has a love defined as homosexuality clearly with Zhan Qingqing (by Pan Huiru).

Different from open media environ ment in Hong Kong, a few plots involved in homosexuality are cautious in the mainland's TV series. In the play, the images of homosexuality aren't indicated directly, but rather expressed by a euphemistic narrative way. In 2008, the Columbia company's city drama Ugly Betty adapted by $\mathrm{Hu}$ Nan television, Chen Jiaming (by Wang Kai) was a talented director looking handsome, fashion and sissy. Comparing to the same role Hugo in the original play who doesn't obscure his homosexual tendency, Chen Jiaming is sissy with a girlfriend, which is surprising.

\section{CONCLUSION}

The publicity of homosexual images in TV series, not only is the behavior of homosexual group, but also relate with the development and changes of the whole society atmosphere. In the Chinese district deepen with moral sense, the homosexual group hasn't still formed a fixed social strength. The homosexual plots existed as social popularity is the reflection of ambiguity and pleasure.

At present, among Chinese TV series including homosexual roles, Hong Kong and Tai Wan TV series show more positive and active in roles' proportion, theme, male and female proportion and characterization. While mainland's TV plays are pretty rough, because discourses of TV screen still are pressed under traditional morality and government censorship restrictions. However, the rapid development of Internet broads a new channel for spreading homosexual theme, and produces a lot of the same theme International drama with big inferences. In 2016, an International drama 《Addiction》 adapted by the same novel, on the many main land's video websites, was played madly. During 24 hours played firstly, ten millions of click rates set the highest click at the first day. Although this play was forbidden to play in mainland by SARFT without the 
end, the International drama with homosexuality theme sprung up among Hong Kong, Tai Wan and mainland.

\section{REFERENCES}

[1] Bian Jing.Film Code: Homosexual [M].Bei Jing: Communication University of China press

[2] Li Yinhe. Subtract[M]. Bei Jing: China Friendship Press, 2002

[3] Zhou Ping. The Evolution and Construct of Homosexual Screen Images[D]. Wuhan University, 2013.

[4] Wang Qian, Chines post-modern vision of a gay Aesthetic Films[D]Guizhou University, 2009. 